\title{
SAMBAQUIS DO ESTADO DO RIO DE JANEIRO: MUSEALIZAÇÃO COMO FORMA DE PRESERVAÇÃO
}

\author{
Alícia Bertoloto 1 \\ Anderson Passos 1 \\ Gabriela Marques ${ }^{1}$ \\ Iuri Pacheco ${ }^{1}$ \\ Luciano Rapagnã ${ }^{1}$ \\ Melanie Lopes ${ }^{1}$ \\ Thayse Bertucci ${ }^{1}$
}

\section{RESUMO}

Sítios arqueológicos distribuídos ao longo da costa brasileira, os sambaquis, evidenciam e permitem a recuperação de informações sobre o homem e o ambiente de milênios atrás através de vestígios deixados por populações humanas. O Sistema Nacional de Unidades de Conservação prevê a preservação desses sítios que pode ser realizada através da criação de Unidades de Conservação ou Museus Arqueológicos. Como consequência, tem-se a valorização e a preservação da história e da memória cultural na ocupação indígena, além da consolidação da proteção ao patrimônio cultural. O presente trabalho consiste na avaliação das leis que conferem a preservação dos sambaquis, no estudo de dois modelos de conservação: Sítio Arqueológico Sambaqui da Tarioba (Rio das Ostras/RJ) e Museu do Sambaqui da Beirada (Saquarema/RJ) e, por fim, na proposta de um modelo de conservação para os Sambaquis da Ilha de Cabo Frio (Arraial do Cabo/RJ) inseridos em uma área de proteção, RESEX-MAR Arraial do Cabo.

Palavras-chave: Vestígios arqueológicos, patrimônio cultural, Unidades de Conservação, Museus Arqueológicos

\begin{abstract}
Archaeological sites distributed along the Brazilian coast, shell mounds, evidence and allow the recovery of information on man and the environment of millennia ago through traces left by human populations. The National System of Protected Areas provides the preservation of these sites that can be accomplished through the creation of Protected Areas or Archeological Museums. As a result, it has the appreciation and preservation of the history and cultural memory of the Indian occupation, as well as the consolidation of protection to cultural heritage. This study consists in the evaluation of the laws that grant the preservation of shell mounds, in the study of two conservation models: Archaeological Site of Sambaqui Tarioba (Rio das Ostras / RJ) and Museum of Sambaqui Beirada (Saquarema / RJ), and, finally, the proposal for a conservation model for Sambaquis of Cabo Frio Island (Arraial do Cabo / RJ) inserted in a protected area, RESEX-MAR Arraial do Cabo.
\end{abstract}

Keywords: Archaeological remains, cultural heritage, Protected Areas, Archaeological Museums

\footnotetext{
${ }^{1}$ Universidade Federal Fluminense, Pós-graduação em Biologia Marinha e Ambientes Costeiros, Campus do Valonguinho, Outeiro São João Batista, s/nº. CEP: 24.020-141, Niterói, Rio de Janeiro, Brasil. E-mail: luciano_rapagna@yahoo.com.br.
} 


\section{INTRODUÇÃO}

Ao percorrer a faixa litorânea do Estado do Rio de Janeiro é possível perceber, em meio à paisagem, vestígios deixados por populações humanas que ocuparam o litoral brasileiro no período de 8.000 a 2.000 anos A.P. ${ }^{2}$, os chamados Sambaquis. Estes sítios arqueológicos estão distribuídos ao longo de quase toda a costa brasileira e, embora não sejam os vestígios mais antigos da pré-história nacional, são excelentes documentos que permitem recuperar informações sobre o homem e o ambiente de alguns milênios atrás. Em consequência, permitem conhecer o processo de transformação cultural vivido por comunidades pré-históricas costeiras (KNEIP, 1997), além de ser uma opção viável para obtenção de informações sobre elevação do nível do mar e mudanças climáticas.

Esses pescadores, coletores e caçadores deixaram como principal testemunho de sua existência uma acumulação artificial, formada basicamente de conchas de moluscos, ossos e carapaças de crustáceos, além de material lítico, sedimentos, vestígios da vida cotidiana e de rituais funerários (PROUS, 1991). Os grandes montes cônicos foram construídos em planícies e encostas, em substratos arenosos ou rochosos, sempre em locais bastante favoráveis à captação alimentar, isto é, próximos a grandes corpos de água devido à sua importância vital. Assim, enseadas, baías, lagunas, restingas e manguezais são exemplos de onde se desenvolveram essas populações, mantendo sempre o contato entre o ambiente marítimo e terrestre, entre a água salgada e doce. Esses ambientes apresentam grande produtividade biótica, o que lhes confere uma alta densidade e diversidade de formas de vida (TENÓRIO, 1996; GASPAR, 1991; LIMA, 2000).

Espaços territoriais que apresentam importantes características naturais e têm como função a manutenção de amostras biológicas de diferentes populações, habitats e ecossistemas do território nacional e das águas jurisdicionais são definidos, pelo Ministério do Meio Ambiente, como Unidades de Conservação (UCs). Após inúmeros debates, criação de Planos e Leis sobre conservação, em 2000 foi criado o Sistema Nacional de Unidades de Conservação (SNUC) que define e regulamenta as categorias de Unidade de Conservação, divididas em dois tipos: Unidades de Proteção Integral e Unidades de Uso Sustentável. As Unidades de Proteção Integral estabelecem normas mais restritas por objetivar a proteção da natureza, sendo permitido apenas o uso de recursos naturais que não envolvem consumo, coleta ou dano aos recursos naturais, como por exemplo, a visitação e a realização de pesquisas. Por sua vez, as Unidades de Uso Sustentável, são áreas que buscam aliar a conservação e o uso dos recursos naturais (MMA-SNUC, 2000).

Segundo Rylands e Brandon (2005), o sucesso das unidades de conservação se dá pela proteção da área que se dispôs a guardar e pela manutenção da diversidade de um país, o que, devido a entraves socioeconômicos e políticos, muitas vezes não é possível. Em áreas de uso sustentável, a dificuldade é ainda maior, pois é difícil definir quem pode utilizar os recursos e qual intensidade não impacta o ambiente. O SNUC ainda prevê a proteção de sítios paleontológicos e arqueológicos e, através da cultura material deixada por povos que

${ }^{2}$ A.P. significa "antes do presente" que por convenção é 1950. Trata-se de uma menção à descoberta da técnica de datação do Carbono 14 que se deu em 1952 (GASPAR, 2000). 
ocupavam essas áreas, amplia-se a importância dos sambaquis e de seus registros, possibilitando o estudo do cotidiano social pré-histórico (TRINDADE, 2001).

Ao longo da costa do Rio de Janeiro, diversas Unidades de Conservação podem ser encontradas e comportam uma diversidade de ecossistemas protegidos, onde estão localizadas zonas arqueológicas, representando um importante campo para pesquisas científicas (SCHELL-YBERT, 2001; INEA, 2010). Considerando que todos esses ecossistemas vêm sofrendo algum tipo de impacto antrópico e tem se intensificado nas últimas décadas, principalmente por conta da urbanização, industrialização e exploração turística, concebe-se a necessidade de preservar esses espaços territoriais de uma forma eficaz. Além da preservação desses sítios através das Unidades de Conservação, é possível observar outra forma de conservação de tais unidades, como é o caso dos Museus. Esse conceito de musealização em sambaquis evidencia a valorização e a preservação da história e da memória cultural na ocupação indígena do Rio de Janeiro, consolidando, juntamente com as UCs, uma proteção ao patrimônio cultural (OLIVEIRA e MONTEIRO de ABREU, 2009).

Desta forma, o objetivo do presente trabalho consiste em comparar e descrever as leis que regem os sambaquis em caráter nacional, bem como comparar os modelos de estrutura e conservação dos Sítios Musealizados como o caso dos Sítios Arqueológicos Sambaqui da Tarioba (Rio das Ostras/RJ) e do Museu do Sambaqui da Beirada (Saquarema/RJ) e propor um possível modelo de conservação para os Sambaquis da Ilha de Cabo Frio (Arraial do Cabo/RJ).

\section{OBJETIVOS}

- Avaliar as leis que regem os sítios arqueológicos no território nacional;

- Analisar sambaquis que apresentam modelos de preservação - Museu do Sambaqui da Tarioba (Rio das Ostras/RJ) e da Beirada (Saquarema/RJ);

- Propor um modelo de musealização para os Sambaquis da Ilha de Cabo Frio (Arraial do Cabo/RJ) inserido em uma Unidade de Conservação (RESEX-MAR Arraial).

\section{MATERIAIS E MÉTODOS}

Os procedimentos metodológicos do presente trabalho permaneceram restritos a pesquisa bibliográfica, tendo como foco as informações dos Sambaquis escolhidos. Foram realizadas buscas a partir de portais como "Periódico Cappes" e "Web of Science". Por outro lado, as buscas referentes às Unidades de Conservação, Leis e Decretos foram encontradas em sites do Ministério do Meio Ambiente (MMA) e do Instituto Estadual do Ambiente (Inea).

\section{a) Área de estudo}


Os Sambaquis estudados neste trabalho estão localizados na porção leste da faixa litorânea do Estado do Rio de Janeiro (Figura 1) e são caracterizados principalmente pela alta presença de conchas depositadas (Figura 2).

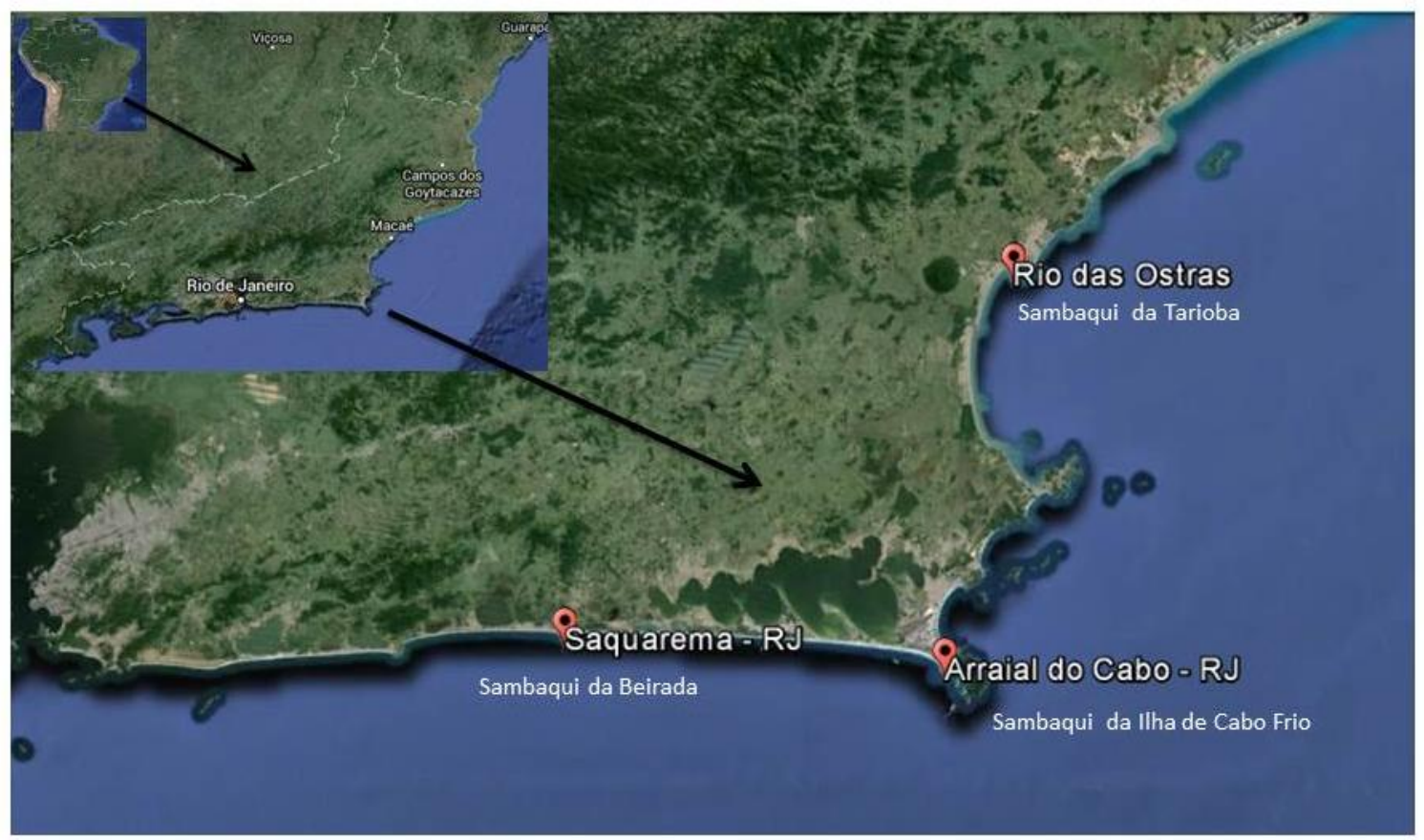

Figura 1 - Mapa da região costeira do Estado do Rio de Janeiro. Vista geral da localização dos sítios estudados.

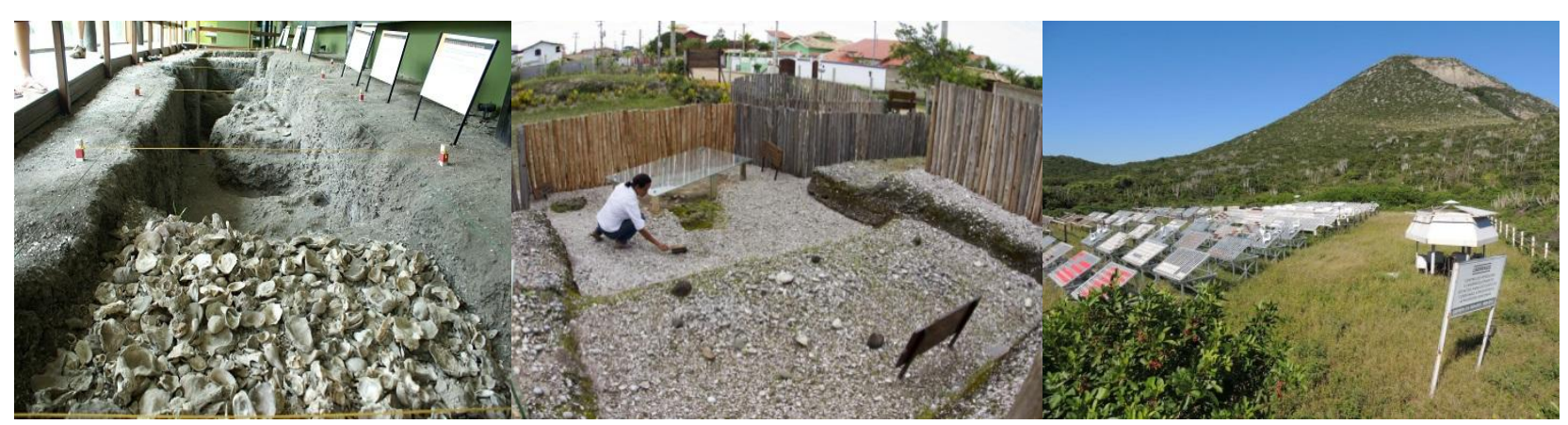
(a) Sambaqui da Tarioba ${ }^{3}$
(b) Sambaqui da Beirada ${ }^{4}$
(c) Sambaqui Usiminas ${ }^{5}$

Figura 2 - Vista dos sítios arqueológicos encontrados na costa do Estado do Rio de Janeiro. (a) Área de escavação do Museu Sambaqui da Tarioba (Rio das Ostras/RJ); (b) Área de escavação do Museu do Sambaqui da Beirada (Saquarema/RJ) e (c) Sambaqui Usiminas - Ilha de Cabo Frio (Arraial do Cabo/RJ).

\section{a. 1) Sambaqui da Tarioba:}

\footnotetext{
${ }^{3}$ Fonte:

http://www.museusdorio.com.br/joomla/index.php?option=com_content $\&$ view=article\&id=88\&Itemid=113

${ }^{4}$ Fonte: http://mapadecultura.rj.gov.br/manchete/museu-do-sambaqui-da-beirada

${ }^{5}$ Fonte: Arquivo Pessoal - Foto Luciano Rapagnã
} 
O Sítio Arqueológico da Tarioba (Figura 2a) situa-se em Rio das Ostras (22³1'40"S, 4156'22"O) no Estado do Rio de Janeiro. Registrado pelo Instituto de Arqueologia Brasileira (IAB) em 1967 e identificado por Ondemar Dias, seu atual presidente, suas escavações tiveram início apenas em janeiro de 1998 com o objetivo de preservar o local e, posteriormente, expor suas características encontradas em um Museu de Sítio. Parte deste sambaqui encontra-se no terreno da Casa da Cultura de Rio das Ostras e somente essa seção permanece em bom estado de conservação, pois o restante foi ocupado por inúmeras construções devido ao avanço da cidade (TRINDADE, 2001).

A unidade arqueostratigrafica consiste em seis camadas e a datação por radiocarbono modelou a probabilidade de início e fim da ocupação da localidade na faixa entre 3.793-3.713 e 3.417-3.266 A.P. (MACARIO et al., 2014). As escavações revelaram ainda um grande vestígio de uma espécie pequena de molusco, a Anomalocardia brasiliana, sendo popularmente conhecido como tarioba, nome o qual deu origem a este sambaqui. Foram encontrados também restos humanos, adornos, ostras gigantes, alguns cacos de cerâmicas, anzóis de concha, carapaças de moluscos, material lítico (batedores e quebra-coquinhos), resíduos alimentares, entre outros materiais (TRINDADE, 2001).

\section{a. 2) Sambaqui da Beirada - Saquarema/RJ:}

Descoberto por morador local e registrado no Instituto do Patrimônio Histórico e Artístico Nacional (IPHAN) em 1975, o sambaqui da Beirada (Figura 2b) situa-se na lagoa de Saquarema (22 $\left.55^{\prime} 28^{\prime \prime S}, 42^{\circ} 32^{\prime} 40^{\prime \prime O}\right)$ no Estado do Rio de Janeiro. Com uma vegetação típica de restinga com espécies de valor alimentar e medicinal, é formado por quatro camadas arqueostratigráficas de ocupações datadas, através de radiocarbono, entre 3.300 e 5.300 A.P. (KNEIP, 1999).

A análise laboratorial do material exumado e a sua datação indicam que esse sítio constitui em uma das ocupações humanas mais antigas registradas até o momento para o Município de Saquarema. De acordo com a Secretaria de Estado de Cultura do Rio de Janeiro, o Sambaqui da Beirada abriga três sepultamentos humanos, além de vestígios de antigas fogueiras, restos alimentares de moluscos (conchas) e peixes, artefatos de pedra e lâminas de machado. Os sambaquis de Saquarema são protegidos por lei federal e tombados pelo IPHAN como fonte de conhecimento sobre a cultura do homem pré-histórico brasileiro (CRANCIO, 2013).

a. 3) Sambaquis da Ilha de Cabo Frio - Arraial do Cabo/RJ:

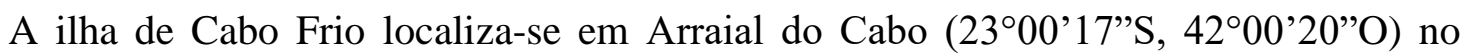
Estado do Rio de Janeiro e possui dois sambaquis: o Sítio da Ilha de Cabo Frio e o Sítio Usiminas (Figura 2c). O primeiro está coberto por duna ainda ativa. Parte dele alcança a faixa de praia e outra está submersa no oceano. A parte emersa compreende uma área de $400 \mathrm{~m}^{2}$. Seu ponto mais alto fica a 20,66 m acima do nível médio do mar atual (TENÓRIO e VILLANGRAN, 2010). O sítio possui uma datação entre $2.360 \pm 40$ e $1.242 \pm 31$ A.P. (ÂNGULO et al., 2007). Além de possuir uma grande diversidade de ossos peixes, moluscos, dentes de tubarões e entre outros, destacam a grande quantidade de ossos humanos espalhados 
na superfície do sítio. Foram retirados seis enterramentos, sendo dois homens jovens, duas mulheres jovens, uma criança/adolescente e um perinatal de 38 semanas (TENÓRIO et al., 2005).

O Sítio Usiminas, por sua vez, está localizado numa área plana, no topo de uma duna consolidada a $53 \mathrm{~m}$ acima do nível do mar. Apresenta uma área em forma de elipse de 1.920 m. A área onde a camada de ocupação é mais densa apresenta estratos bem definidos que somam $160 \mathrm{~m}$ de espessura. O local, mesmo distante das fontes de recursos alimentares, oferece excelente visibilidade e está próximo de uma formação de rocha magmática de boa qualidade para produção de instrumentos (TENÓRIO e VILLANGRAN, 2010). O sítio está datado entre $2.068 \pm 31$ e $1.437 \pm 34$ A.P. (ÂNGULO et al., 2007). Acredita-se tratar de um local para rituais fúnebres em decorrência dos enterramentos humanos encontrados na base das duas trincheiras escavadas no sítio (TENÓRIO e VILLANGRAN, 2010).

\section{RESULTADOS E DISCUSSÕES}

\section{Leis de preservação em sítios arqueológicos}

Os bens materiais e imateriais, tangíveis e intangíveis que compreendem o patrimônio cultural são considerados "manifestações ou testemunho significativo da cultura humana", reputados como imprescindíveis para a conformação da identidade cultural de um povo (ZANIRATO e RIBEIRO, 2006) e por isso precisam ser preservados. Apresenta-se a seguir legislações vigentes em nível federal acerca do patrimônio cultural arqueológico. Uma das primeiras leis que tratam sobre o patrimônio cultural e incluiu sambaquis é a Lei Federal $\mathrm{n}^{\circ}$ 3.924, de 26 de julho de 1961. Esta regulamentou os achados arqueológicos e pré-históricos:

Art. $1^{\circ}$ Os monumentos arqueológicos ou pré-históricos de qualquer natureza existentes no território nacional e todos os elementos que neles se encontram ficam sob a guarda e proteção do Poder Público, de acordo com o que estabelece o art. 175 da Constituição Federal.

Parágrafo único. A propriedade da superfície, regida pelo direito comum, não inclui a das jazidas arqueológicas ou pré-históricas, nem a dos objetos nelas incorporados na forma do art. 152 da mesma Constituição. históricos:

Art. $2^{\circ}$ Consideram-se monumentos arqueológicos ou pré-

a) as jazidas de qualquer natureza, origem ou finalidade, que representem testemunhos de cultura dos paleoameríndios do Brasil, tais como sambaquis, montes artificiais ou tesos, poços sepulcrais, jazigos, aterrados, estearias e quaisquer outras não especificadas aqui, mas de significado idêntico a juízo da autoridade competente.

A Lei Federal ficou conhecida como a "Lei dos Sambaquis" por ser a primeira a inclui-los como achados arqueológicos de valor e identidade cultural, ainda, a apontar 
medidas punidoras a destruição ou mutilação dos monumentos. No que tange à participação social, a Constituição Federal de 1988 definiu no parágrafo $1^{\circ}$ do artigo 216 :

Art. 216. Constituem patrimônio cultural brasileiro os bens de natureza material e imaterial, tomados individualmente ou em conjunto, portadores de referência à identidade, à ação, à memória dos diferentes grupos formadores da sociedade brasileira, nos quais se incluem:

$\S 1^{\circ} \mathrm{O}$ poder público, com a colaboração da comunidade, promoverá e protegerá o patrimônio cultural brasileiro, por meio de inventários, registros, vigilância, tombamento e desapropriação, e de outras formas de acautelamento e preservação.

A preservação do patrimônio histórico, cultural e paisagístico da humanidade e o reconhecimento da pluralidade de valores e diversidade cultural da sociedade moderna têm tomado espaço na mídia e no cenário político mundial. Agências internacionais vêm incentivando a formulação de projetos voltados para o fomento do turismo cultural e do desenvolvimento sustentável em diversas regiões do planeta, inclusive no Brasil, que destacam o potencial turístico de centros históricos e parques ecológicos, não raro estimulam a exploração de rotas ou itinerários culturais em diversos Estados da União (PELEGRINI, 2006).

O ritmo de desenvolvimento urbano, a mercantilização da cultura e da natureza são grandes ameaças à sobrevivência do patrimônio cultural e natural. A proteção, por sua vez, ocorre por meio de medidas políticas destinadas a impedir que essas ameaças que degradam o ambiente venham a destruir um dado bem. Para que essa ação estatal se efetive é necessário que haja mobilização social que leve o governo a adotar políticas de proteção (ZANIRATO, 2009).

Um planejamento para conservação integrada estabelece o cruzamento entre dois eixos, sendo um que abrange os aspectos econômicos, sociais, físico-territoriais e administrativo-institucional, e o outro que compreende os níveis e esferas da estrutura institucionalizada em: municipal, regional, estadual e nacional (PONTUAL, 2002). Diante das informações apresentadas, tem-se por gestão o conjunto de ações - do planejamento à execução - voltada à conservação do patrimônio. A musealização de um sítio arqueológico pode vir a ser uma das maneiras mais eficazes para a preservação e conscientização cultural da população.

\section{Musealização em Sambaquis - Caso de estudo: Tarioba e Beirada}

Mesmo sem saber a real causa do desaparecimento da população sambaquieira, acredita-se na importância de preservar histórias e memórias literalmente subterrâneas destes povos que foram dizimados provavelmente em disputas por territórios na época do descobrimento. O desaparecimento físico impede a reconstrução das memórias através da 
oralidade, como ocorre em outros grupos sociais, sendo possível apenas a reconstrução da história a partir dos vestígios da cultura material e dos restos humanos. Neste caso, a memória pode ser acessada exclusivamente por mediadores, especialmente pesquisadores das áreas de arqueologia, museologia, história, biologia e afins (OLIVEIRA, 2011).

Visando o contexto, o Museu de Arqueologia do Sambaqui da Tarioba foi inaugurado em 1999, tendo como objetivo apresentar a cultura do homem sambaquieiro que habitou a região de Rio das Ostras no passado, mostrando sua distribuição espacial e suas características biológicas (OLIVEIRA, 2011). Com abertura para visitação pública, consiste em exposições permanentes com peças organizadas por período, origem e tipo determinados pelos arqueólogos do IAB, maquetes, artefatos expostos em vitrines, mapas e reconstituições. A partir de atividades direcionadas a escolas e pesquisadores, a musealização do Sambaqui da Tarioba incentivou a preservação do sítio e de seu material arqueológico in situ, além de promover o desenvolvimento econômico do município através do atrativo turístico decorrente (TRINDADE, 2001).

Durante as escavações, foram encontradas vinte ossadas humanas das quais quatro estão expostas da maneira como foram encontradas, demarcando uma das características mais significativas do Sítio Arqueológico, ou seja, todo o material exposto é deixado da maneira como foi encontrado. Esta característica, apesar de despertar o interesse dos visitantes, pois permite o transporte a uma época passada, expõe as peças encontradas no museu e coloca o próprio local aos riscos da visitação, como quebra de materiais, desaparecimento de peças e alteração das características originais que ainda não foram exploradas. No entanto, a exposição fornece um elo entre as transições da natureza e as transformações da cultura préhistórica, revelando a importância dos sambaquieiros para a memória nacional. Desta forma, para que a memória e a história sejam preservadas, deve haver um uso racional do local e manutenção constante aliada à supervisão durante as visitas (OLIVEIRA, 2011).

O segundo processo de musealização estudado foi o Sambaqui da Beirada. Trata-se do primeiro museu de arqueologia ao ar livre no Brasil. Com área de $7.000 \mathrm{~m}^{2}$ e cercado por tela aramada, abriga um conjunto arqueológico e paisagístico de grande importância científica, cultural e turística, expondo e preservando in situ, em espaço aberto à visitação pública, testemunhos de um sítio arqueológico pré-histórico do tipo sambaqui. Este sítio foi amplamente estudado pela arqueóloga e professora Lina Kneip, grande especialista do Museu Nacional/UFRJ no estudo dos sambaquis. No período de 1975 a 1978, Lina apresentou, às autoridades municipais de Saquarema, um projeto sugerindo a criação de uma "Reserva Arqueológica e Ecológica de Barra Nova" que, no entanto, não foi outorgado na época. O sambaqui da Beirada foi pesquisado no decorrer de 1987, por uma equipe coordenada pela própria professora, através do projeto "Pesquisa Pré-histórica e Paleoambiente de Saquarema" e "Preservação do Patrimônio Pré-histórico do Estado do Rio de Janeiro", do Museu Nacional. Em 31 de maio de 1997, foi inaugurada a Praça do Sambaqui da Beirada como resultado (VELOSO e CAVALCANTI, 2007; CRANCIO, 2013).

Segundo PARDI (2007), o Sambaqui da Beirada está enquadrado, dentre os três modelos de uso turístico dos bens arqueológicos, no Modelo de Pequeno Porte. Este modelo 
envolve iniciativas dos municípios, comunidades, iniciativa privada e pessoas físicas e abrange áreas de projeto de pequeno porte com um ou mais sítios com entorno ambiente, com nível de intervenção tolerável, com aporte de capitais eminentemente privados, efetuado com proteção legal, gestão de curto e médio prazo, apoio eventual de profissionais especializados em arqueologia e da comunidade. Analisando o Museu de Sítio Arqueológico Praça do Sambaqui da Beirada, VELOSO e CAVALCANTI (2007) identificaram as seguintes estratégias de apresentação do patrimônio arqueológico:

i) o desenvolvimento de pesquisas por instituição governamental - Museu Nacional do Rio de Janeiro;

ii) apresentação de vestígios in situ, para o público em geral, através de uma mostra arqueológica modular que expõem as evidências no plano vertical (pequenos perfis) e no plano horizontal (solos expostos pela decapagem). Segundo KNEIP (1999), procurou-se mostrar aos visitantes, que o sambaqui é um antigo local de moradia de sociedades pescadoras, coletoras e caçadoras pré-históricas, onde o homem desenvolvia uma série de atividades domésticas, artesanais e cerimoniais;

iii) proteção física da área arqueológica, que corresponde à área escavada do sambaqui. A área é cercada por toras de eucalipto tratado, sendo que os sepultamentos são cobertos por placas de vidro blindex incolor e a cobertura protetora permite aos visitantes observar os vestígios. Além disso, os esqueletos humanos localizados foram protegidos com solução de resina e estão sendo gradativamente substituídos por réplicas confeccionadas em resina de poliéster;

iv) área expositiva, que conta com placas informativas e placas explicativas;

v) desenvolvimento de ações educativas de Educação Patrimonial, através de palestras e encontros e de ações de envolvimento da comunidade. Essas ações são realizadas desde 1987 e estão apoiadas em fundamentos metodológicos e práticos que visam despertar na comunidade e no público em geral, a formação de valores culturais passados, além de informar aos visitantes sobre a riqueza da flora e fauna local;

vi) desenvolvimento de um plano de manejo que categorizou sua área interna (esta está dividida em três espaços, a saber: Zona 1 que corresponde à zona arqueológica; Zona 2, que abarca a zona primitiva ou melhor, original do sambaqui e a Zona 3, de uso intensivo), além de visitas guiadas e mediante agendamento e controle de visitantes que é feito através de registro em livro contendo nome, procedência e profissão;

vii) implantação de um Centro de Informação e Apoio ao Visitante com sala de vídeo, banheiros e loja de souvenir.

\section{Propostas para os Sambaquis da Ilha de Cabo Frio - Arraial do Cabo/RJ:}

Transformar sítios arqueológicos em Museus a céu aberto, ou seja, musealizar se faz importante para colaborar com a proteção do patrimônio conforme o que estabelecem outorgas legais como: a Lei Federal 3.924/61; a Portaria SPHAN de 07/88; a Resolução 
CONAMA 001/86; a Portaria IPHAN de 299/04, bem como as diretrizes do ICOMOS Conselho Internacional dos Monumentos e Sítios Históricos (IPHAN, 2013).

Arraial do Cabo é um município que possui além dos sambaquis mencionados neste estudo, os sambaquis: Abrigo Praia dos Anjos, Massambaba II, Sambaqui do Morro da Concha, Sítio Arqueológico da Ponta da Cabeça, Sítio Arqueológico Dunas da Praia Seca, Sítio Colônia de Pesca ZP-05, Sítio do Boqueirão, Sítio Praia dos Anjos. Trata-se também de uma RESEX-MAR, inserida na Unidade de Conservação de Uso Sustentável, sendo criada com o objetivo de garantir proteção ao ambiente bem como a população tradicional. Assim, tendo em vista os benefícios que o processo de musealização pode trazer para um sítio arqueológico, ambos os sambaquis da Ilha do Farol, bem como os demais sambaquis de Arraial do Cabo, carecem de estratégias para a implantação deste processo. Torna-se essencial uma vez que garante à população tradicional o resgate de sua história natural, além de servir de atrativo para visitantes e turistas, possibilitando o desenvolvimento da economia local.

O processo de Muselização dos Sambaquis da Ilha de Cabo Frio deveriam seguir as estratégias descritas acima por VELOSO e CAVALCANTI (2007), utilizadas no sambaqui da Beirada, onde fosse promovido o desenvolvimento de pesquisas, a apresentação de vestígios in situ para o público em geral, proteção física da área arqueológica, uma área expositiva, que conta com placas informativas e placas explicativas, o desenvolvimento de ações educativas de Educação Patrimonial, através de palestras e encontros e de ações de envolvimento da comunidade, o desenvolvimento de um plano de manejo, bem como a implantação de um Centro de Informação e Apoio ao Visitante com sala de vídeo, banheiros e loja de souvenir.

\section{CONCLUSÕES}

O aproveitamento do patrimônio arqueológico é uma prática recorrente em diversas partes do mundo, além de constituir uma fonte de recursos financeiros para o munícipio em que estão inseridos. No Brasil, esse uso com finalidade turística ainda é incipiente, mesmo diante de um extenso recurso arqueológico encontrado em praticamente toda a costa. $\mathrm{O}$ turismo cultural vem se tornando uma nova fonte de atrativo, visando não só atender a crescente demanda do segmento, bem como a formatação de produtos diferenciados. A utilização deste patrimônio de cultura material de forma sustentável, além de exigir constante manutenção de seus recursos, procura, sobretudo, preservar o objeto de visitação, podendo ser visto como uma alternativa de preservação e uma fonte permanente de recursos, empregos e envolvimento comunitário.

Deste modo, os processos de musealização de sítios arqueológicos são fundamentais na recepção e valorização do patrimônio arqueológico, como estratégia de preservação. Esta iniciativa garante não apenas a integridade física de uma cultura material, mas também incentiva projetos de pesquisa e a criação de documentos voltados à produção, registro e disseminação das informações a eles relacionadas. Os dois exemplos estudados, Sambaqui da Tarioba e da Beirada, apresentam processos de musealização em que o patrimônio arqueológico pôde ser preservado a partir desta iniciativa. Assim, o maior desafio para uma proposta de musealização de um patrimônio arqueológico inserido em Unidades de 
Conservação, como no caso dos Sambaquis da Ilha de Cabo Frio, incide na adequação das políticas públicas e integrações de programas de intervenções culturais nos Planos de Manejos, assegurando, assim, um instrumento de proteção e planejamento para a promoção e divulgação dos bens culturais contidos nestas áreas.

\section{REFERÊNCIAS BIBLIOGRÁFICAS}

ÂNGUlO, R. J.; REIMER, P. J.; De SOUZA, M. C.; SCHEEL-YBERT, R.; TENÓRIO, M. C.; DISARÓ, S. T.; GASPAR, M. D. A tentative determination of upwelling influence on the paleo-surficial marine water reservoir effect in Southeastern Brazil. Radiocarbon, 49 (3): 1255-1259. 2007.

CRANCIO, F. A pré-história de Saquarema preservada na Praça do Sambaqui da Beirada. O SAQUÁ - O Jornal de Saquarema, Edição 158. 2013.

GASPAR, M. D. Aspectos da organização social de um grupo de pescadores, coletores e caçadores que ocupou o litoral do Estado do Rio de Janeiro. Tese de Doutorado, Faculdade de Filosofia, Letras e Ciências Humanas, Universidade de São Paulo, Brasil, 362 p. 1991.

GASPAR, M. D. Sambaqui: arqueologia do litoral brasileiro. Ed. Jorge Zahar, Rio de Janeiro, 89 p. 2000.

INEA - Instituto Estadual Do Ambiente. Plano de Manejo do Parque Estadual da Ilha Grande. 2010. - ANEXOS - Disponível em :

<http://www.inea.rj.gov.br/cs/groups/public/documents/document/bmvh/mdey/ edisp/inea01 2818.pdf> Acesso: 05/05/2015.

IPHAN. Carta Lousanne preparada pelo Comité Internacional para a Gestão do Património Arqueológico (ICAHM) e adotada pela $9^{\mathrm{a}}$ Assembléia Geral do ICOMOS, realizada em Lausanne em $1990 . \quad$ Disponível em: <http://portal.iphan.gov.br/portal/baixaFcdAnexo.do?id=262> Acesso: 23/04/2015.

KNEIP, L. M. O Sambaqui do Saco e de Madressilva - Saquarema, RJ. Documento de Trabalho, Série Arqueologia, Museu Nacional/UFRJ, nº 4, 67 p. 1997.

KNEIP, L. M. Preservação e Proteção do Patrimônio pré-histórico de Saquarema/RJ. Rio de Janeiro, Museu Nacional/UFRJ, (texto impresso). 1999.

LIMA, T.A. Em busca dos frutos do mar: os pescadores-coletores do litoral centro-sul do Brasil. Revista da USP, 44: 270-327. 2000.

MACARIO, K. D.; SOUZA, R. C. C. L.; TRINDADE, D. C.; DECCO, J.; LIMA, T. A.; AGUILERA, O. A.; MARQUES, A. N.; ALVES, Q. E.; OLIVEIRA, F. M.; CHANCA, I. S.; CARVAlHO, C.; ANJOS, R. M., PAMPlONA, F. C.; SILVA, E. P. Chronological Model Of A Brazilian Holocene Shellmound (Sambaqui Da Tarioba, Rio De Janeiro, Brazil). Radiocarbon 56 (2): 489-499. doi: 10.2458/56.16954. 2014.

MMA (Ministério do Meio Ambiente) - SNUC (Sistema Nacional de Unidades de Conservação) 2000. Disponível em:

http://www.mma.gov.br/estruturas/250/_publicacao/250_publicacao30082011035301.pdf>

Acesso: 01/05/2015. 
OLIVEIRA, R. A.; MONTEIRO de ABREU, R. M. R. Relações entre memória, história e o Museu de Arqueologia Sambaqui de Tarioba: Diálogos Póssiveis. XIV Encrontro Regional da ANPUH-Rio, Memória e Patrimônio. 2009.

OLIVEIRA, R. A. Memórias da ocupação indígena no Estado do Rio de Janeiro: Um estudo de caso do Museu de Arqueologia Sambaqui da Tarioba. Dissertação de Mestrado em Memória Social, Universidade Federal do Estado do Rio de Janeiro, Rio de Janeiro, 247 f. 2011.

PARDI, M.L.F. A Preservação do Patrimônio Arqueológico e Turismo. Revista do Patrimônio Histórico e Artístico Nacional, 33: 305-337. 2007.

PELEGRINI, S.C.A. O patrimônio cultural no discurso e na lei: trajetórias dos debates obre a preservação no Brasil. Patrimônio e Memoria. UNESP - FCLAs - CEDAP, v.2, n.2, p. 54. 2006.

PONTUAL, V. A referência cultural e o planejamento da conservação integrada. In: Gestão do Patrimônio Cultural Integrado. Jukkia Jokilehto et al. (orgs.) Ed. Universitária da UFPE: Recife. 2002.

PROUS, A. Arqueologia Brasileira. Ed. Universidade de Brasília, Brasília, DF, 605 p. 1991.

RYLANDS, A.B. e BRANDON, K. Unidades de conservação brasileiras. Megadiversidade, 1 (1): 27-35. 2005.

SCHELL-YBERT, R. Os vegetais da vida dos sambaquieiros. Revista Ciência Hoje, 28: 16:31. 2000.

SCHELL-YBERT, R. Man and vegetation in Southeastern Brazil during the Late Holocene. Journal of Archaeological Science. 28: 471 - 480. 2001.

SECRETARIA DE ESTADO DE CULTURA DO RIO DE JANEIRO - Mapa de Cultura RJ, Petrobrás. Disponível em: <http://mapadecultura.rj.gov.br/manchete/museu-do-sambaquida-beirada> Acesso: 22/04/2015.

TENÓRIO, M. C. A contribuição da Arqueologia na compreensão do desenvolvimento do mangue. Boletim do Museu Paraense Emílio Goeldi, Série Ciências da Terra, 8: 123-136. 1996.

TENORIO, M. C.; RODRIGUES-CARVALHO, C; LÍRYO, A.; PINTO, D. C.; LIMA, R. A. Estrutura de cremação no sítio da Ilha de Cabo Frio. Resumos do XIII Congresso da Sociedade de Arqueologia Brasileira. Campo Grande. 2005.

TENÓRIO, M.; VILLAGRAN, X. Dinâmica espacial e assentamentos domésticos nos sambaquis da Ilha de Cabo Frio (Rio de Janeiro). In: XV Congresso da Sociedade de Arqueologia Brasileira, Belém Sociedade Brasileira de Arqueologia. 2010.

TRINDADE, D.C. Arqueologia e memória: o caso da musealização do Sambaqui da Tarioba. Fundaçao Rio das Ostras de Cultura: Inside, Rio das Ostras, RJ. 80 p. 2001.

VELOSO, T. P. G.; CAVALCANTI, J. E. A. O turismo em sítios arqueológicos: algumas modalidades de apresentação do patrimônio arqueológico. Revista de Arqueologia, 20: 155-168. 2007.

ZANIRATO, S. H.; RIBEIRO, W. C. Patrimônio cultural: a percepção da natureza como um bem não renovável. Revista Brasileira de História. São Paulo, v. 26, no 51, p. 251-262. 2006. 
ZANIRATO, S. H. Usos sociais do patrimônio cultural e natural. Patrimônio e Memoria. UNESP - FCLAs - CEDAP, v. 5, n.1, p. 137-152 - out. 2009. 